\title{
Influence of Low-Dose Neonatal Domoic Acid on the Spontaneous Behavior of Rats in Early Adulthood
}

\author{
K. JANDOVÁ ${ }^{1}$, P. KOZLER ${ }^{1}$, M. LANGMEIER ${ }^{1}$, D. MAREŠOVÁ ${ }^{1}$, J. POKORNÝ ${ }^{1}$, \\ V. RILJAK ${ }^{1}$ \\ ${ }^{1}$ Institute of Physiology, First Faculty of Medicine, Charles University in Prague, Prague, Czech \\ Republic
}

Received March 16, 2014

Accepted August 10, 2014

\begin{abstract}
Summary
Consumption of seafood containing toxin domoic acid (DA) causes an alteration of glutamatergic signaling pathways and could lead to various signs of neurotoxicity in animals and humans. Neonatal treatment with domoic acid was suggested as valuable model of schizophrenia and epilepsy. We tested how repeated early postnatal DA administration influences the spontaneous behavior of rats in adulthood. Rats were injected with $30 \mu \mathrm{g} \mathrm{DA} / \mathrm{kg}$ from postnatal day (PND) 10 until PND 14. Their behavior was observed in the open field test for one hour (Laboras, Metris) at PND 35, PND 42 and PND 112. We did not find any difference between DA treated rats and animals injected with equivalent volume of saline in both test sessions at PND 35 and PND 42. DA rats at PND 112 exhibited significantly higher vertical and horizontal exploratory activity (tested parameters: locomotion, distance travelled, average speed reached during test, grooming and rearing) between the 30th-40th min of the test session and habituated over 10 min later. We conclude that at least in the given experimental design, neonatal DA treatment results in alteration of the spontaneous behavior of rats in adulthood.
\end{abstract}

\section{Key words}

Domoic acid • Locomotor activity • Open field test • Rat

\section{Corresponding author}

K. Jandová, Institute of Physiology, First Faculty of Medicine, Charles University in Prague, Albertov 5, CZ -128 00, Prague 2, Czech Republic. E-mail: katerina.jandova@lf1.cuni.cz

\section{Introduction}

Domoic acid (DA) is a water-soluble tricarboxylic amino acid produced by diatom Pseudonitzschia, which contaminates shellfish and other type of seafood. Consumption of them can lead to DA intoxication of sea mammals, birds and finally humans. DA intoxication causes in human the clinical syndrome "Amnesic shellfish poisoning" (ASP) accompanied by gastrointestinal (nausea, vomiting, abdominal cramps, diarrhea) and neurological (headache, disorientation, confusion, coma, seizure and memory loss) symptoms. This diagnosis was first established during human DAintoxication in 1987 in Canada with 107 people (Wright et al. 1989, Perl et al. 1990, Todd 1993, Pullido et al. 2008).

DA is structurally related to kainic acid. Both excitatory amino acids are analogues of glutamate, the major excitatory neurotransmitter in the brain. DA binds to presynaptic and postsynaptic ionotropic AMPA and kainite (KA) subtype of glutamate receptors and causes then an increase of the intracellular $\mathrm{Ca}^{2+}$ ions resulting in glutamate release and then activation of NMDA receptors. These combined actions are involved in the neuronal death in some sensitive brain regions, preferentially in the limbic system like hippocampus and amygdala (Stewart et al. 1990, Scallet et al. 1993, Berman and Murray 1997, Chandrasekaran et al. 2004, Costa 2010). While higher concentrations of DA induce necrotic cell death, low concentration of DA leads to apoptotic changes in neurons (Giordano et al. 2006, 2007, 2009). In animal model (rats and mice) administration of DA induces neurotoxic syndrome including broad spectrum of the dose-dependent behavioral patterns like scratching, tremor, seizures, wet dog shakes and influences the locomotor activity (Peng 
and Ramsdell 1996, Grant et al. 2010).

In our experiment we aimed to examine and quantify long-term effect of repeated DA injections in low dose during early development. We hypothesized that locomotor activity of experimental animals will be increased by repeated low dose of DA and that this effect will persist till early adulthood.

\section{Materials and Methods}

\section{Experimental animals}

Twenty naive male Wistar albino rats were used in this experiment (ten treated with DA, ten injected with corresponding volume of saline). All animals were bred at the Institute of Physiology, 1st Faculty of Medicine, Charles University in Prague. Dams and litters were housed in standard $12 \mathrm{~h}$ light/dark cycles (with lights on at 6:00 h) in temperature-controlled environment (22$23^{\circ} \mathrm{C}$ ) with food and water provided ad libitum. The day of parturition was designed as postnatal day 0 (PND 0). Within $24 \mathrm{~h}$ after the birth, male rat were culled to 10 pups per litter and with the exception of routine cage clearing, were left undisturbed until the beginning of experimental procedures. Pups were weaned at 28 days (PND 28) with two to three rats per cage, and then housed PND 112.

On the PND 10, pups were weighed, marked with non-toxic permanent pen for identification and assigned to two experimental groups. Half the males within each litter received a single injection of $30 \mu \mathrm{g} / \mathrm{kg}$ DA over PND 10-14, other half received equal volume of saline. DA (Sigma) was dissolved in sterile saline and injections were administered subcutaneously (s.c.) in volume of $10 \mathrm{ml} / \mathrm{kg}$.

On PND 35 all animals were placed and tested in Laboras apparatus (Metris B.V., Netherlands) for one hour to analyze their behavioral pattern (test day 1 - PND 35). During the measurement animals were left undisturbed. After the test session animals were returned to their home cages and housed for another seven days (food and water ad libitum). After that period all animals were placed in Laboras apparatus again and their behavioral pattern was observed for the period of one hour (test day 2 - PND 42). Finally, the last third measurement was conducted on PND 112 under the same conditions (test day 3 - PND 112).

All experiments were reviewed and approved by the Institutional Animal Care and Use Committee and are in agreement with the Czech Government Requirements and Requirements of European Communities Council Directive (86/609/EEC).

\section{Laboras apparatus (Metris, B.V., Netherland)}

Laboras $^{\mathrm{TM}}$ is automated system for continuous behavior tracking and analysis. It consists of triangular shaped sensing platform (carbon fiber plate $700 \mathrm{~mm} \mathrm{x}$ $700 \mathrm{~mm} \times 1000 \mathrm{~mm} \times 30 \mathrm{~mm}$ ), positioned on two orthogonally placed sensor transducers and third fixed point attached to bottom plate. Makrolon cage (type III, $\left.840 \mathrm{~cm}^{2}\right)$ is placed on this platform. Mechanical vibrations generated by the animal (locomotion, rearing etc.) are transformed into electrical signal. Such signals are finally processed, classified and compared with the predetermined characteristic patterns by Laboras software. We analyzed following horizontal behavioral activities: time of locomotion, average speed in tested interval and total distance travelled in tested interval. Vertical activities included rearing time and rearing frequency (exploratory behavior), the time spent by grooming and the grooming frequency (comfort behavior) were also evaluated.

\section{Statistical analysis}

Data from Laboras software were analyzed over ten minutes' intervals (0-10 $\mathrm{min}, 10-20 \mathrm{~min}, 20-30 \mathrm{~min}$, 30-40 min, 40-50 min, 50-60 min). Each measured behavioral parameter was analyzed separately. Laboras data were subjected to non-parametric tests (because of non-Gaussian data distribution). To compare the differences between individual groups within $10 \mathrm{~min}$ intervals Kruskal-Wallis test was used, if $p<0.05$ results were considered as significant.

\section{Results}

All animals treated with DA (or saline) survived. Weight gain of 35-day-old rats treated with DA was not different $(92 \pm 5.9 \mathrm{~g})$ after the last injection of DA when compared with saline treated rats $(88 \pm 7.3 \mathrm{~g})$.

\section{Test day $1-P N D 35$}

In the youngest age group (35-day-old animals), monitored at the $21^{\text {st }}$ day after the last dose of DA, no significant changes in the behavior, compared to control offspring, were observed. In the course of six 10 min intervals, not even one of the parameters of horizontal and vertical activity and comforting behavior (grooming) manifested statistically different behavioral 
patterns. While both groups of animals in the first half of the experiment were active (getting acquainted with the new environment), in the second part the activity of the offspring was almost zero (sign of habituation) (Fig. 1).

\section{Test day 2 - PND 42}

Figure 2 shows the results of the spontaneous activity monitoring in 42-day-old animals, 28 days after the last administration of DA. Again, no significant differences in the behavior of animals between the two groups were observed. The graphs indicate nearly identical waveform locomotor activity; distance and average speed during the measurement, as well as the course of rearing (HR explorative behavior) were identical in both groups.

\section{Test day 3-PND 112}

Last monitoring was performed 98 days after the treatment with DA in 112-day-old animals. The results (see Fig. 3) bring a different pattern of behavior of DA animals in all parameters. In the first $30 \mathrm{~min}$ of the experiment, no significant differences in the horizontal activity were observed, i.e., the locomotor activity, distance, and the average speed of DA animals did not differ from the values of the control group. Between the 2nd to 4th intervals, the measured parameters in DA animals stabilized at a constant value. The activity in the interval between the 30th and 40th min significantly increased compared to control animals (locomotion, $\mathrm{p}<0.01$, the average speed, $\mathrm{p}<0.01$, distance, $\mathrm{p}<0.01)$. The same course was observed in indicators of vertical activity with a difference in the second interval where the time spent by rearing was significantly lower $(p<0.01)$ than in control animals. Between the $30^{\text {th }}-40^{\text {th }} \mathrm{min}$, DA animals showed higher rearing activity $(\mathrm{p}<0.01)$ and frequency of rearing $\mathrm{p}<0.01)$. Analysis of the last parameter, the so-called comfort behavior (frequency of grooming and grooming) follows results of previously described behavioural parameters. In both cases a significantly higher activity was registered between the $30^{\text {th }}-40^{\text {th }}$ min of the experiment.

\section{Discussion}

Because the rats are about 20 to 40 times less sensitive to orally administered DA than humans, parenteral administration was chosen, resp. s.c. in our experimental paradigm (Iverson et al. 1989). Biochemical, morphological and behavioral changes induced by DA treatment depend not only on the route of application, gender, but primarily on the administered dose for the given age (Grant et al. 2010, Costa et al. 2010). Previous studies indicate that the daily treatment with very low doses of DA $(20 \mu \mathrm{g} / \mathrm{kg}$ s.c. $)$ in the second postnatal week (between PND 8-14) causes behavioral and cognitive changes and these changes persist into adulthood (Doucette et al. 2003, 2004, Levin et al. 2005, Bernard et al. 2007, Burt et al. 2008, Adams et al. 2008, Adams et al. 2009, Perry et al. 2009, Marriott et al. 2012). Our study extends those works and with the help of automated observation system LaborasTM we analyzed spontaneous locomotor activity, exploratory behavior (rearing) and grooming (comfort behavior) of male rats. In our experiment single doses of DA were higher (five times single dose $30 \mu \mathrm{g} / \mathrm{kg}$ s.c. in PND 1014) when compared with the above- cited works, but the total dose administered was similar. We hypothesized that the application of the neurotoxin during critical period of CNS development, as the first three weeks of postnatal life are called (brain maturation during the first 2 weeks of postnatal life is likened to the development of the human brain in the last trimester of pregnancy) (Dobbing and Sands 1979) affects the spontaneous behavior during early ontogeny and early adulthood. Results of our experiment show that exposure to low doses of DA in the early postnatal period did not affect any of the monitored parameters of horizontal and vertical activity of young animals (35-day- and 42-dayold). These results correspond with the findings of the study by Doucette et al. (2003) where in a similar experimental protocol no changes in locomotor activity in the open field arena manifested. Significant differences in the behavior of our animals occurred only in adult animals (at PND 112). Experimental rats showed a different pattern of behavior, and habituation occurred 10 min later than in the control animals. While the behavior of DA treated rats in the first $30 \mathrm{~min}$ of experiment did not differ from that of control animals (with the exception of rearing), between $30^{\text {th }}-40^{\text {th }}$ min DA group of animals showed significantly higher locomotor activity and at a higher average speed they covered a greater distance. The same course was observed in the parameters of exploratory behavior (rearing) and comfortable behavior (grooming), the total time spent and frequency were increased in the second half hour of monitoring in the open field test in comparison with the control group. These findings correspond to the results of work by Burt et al. (2008) that demonstrated the 


\section{test day 1 - PND 35}

\section{Locomotion}

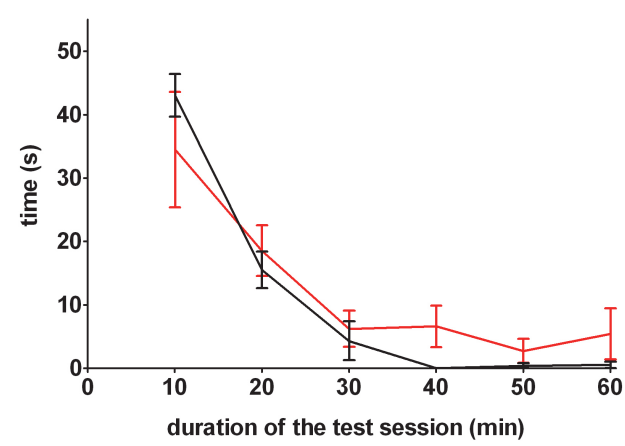

Distance

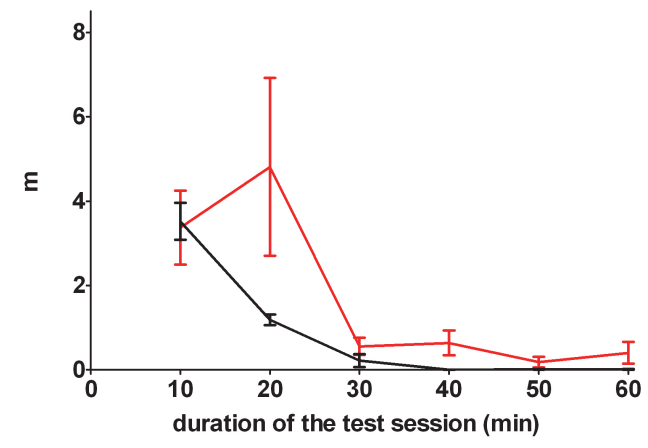

Rearing

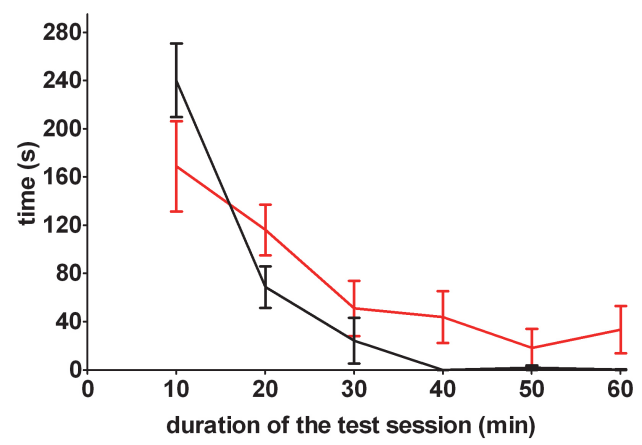

Grooming

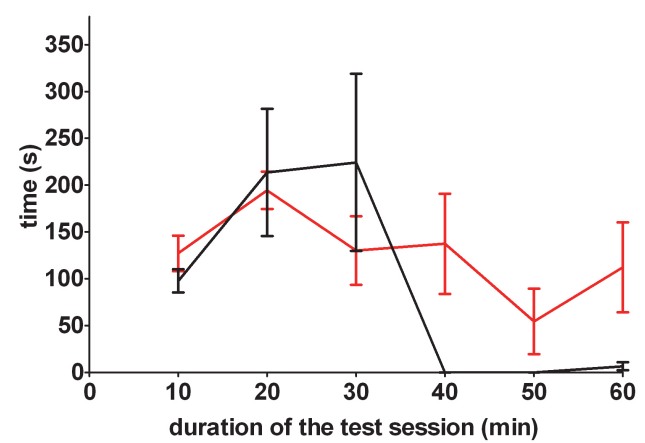

Average speed

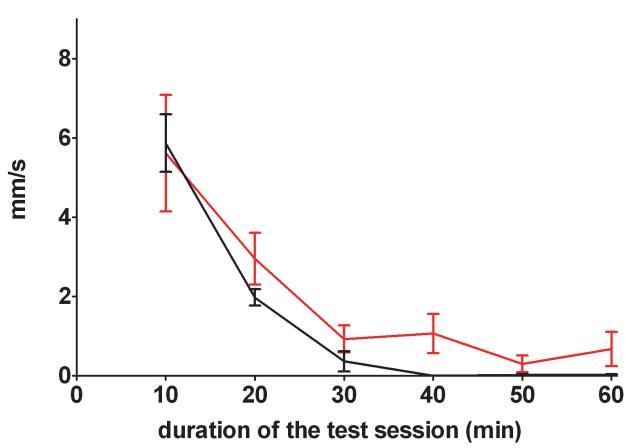

duration of the test session ( $\mathrm{min}$ ) 


\section{test day 2 - PND 42}

\section{Locomotion}

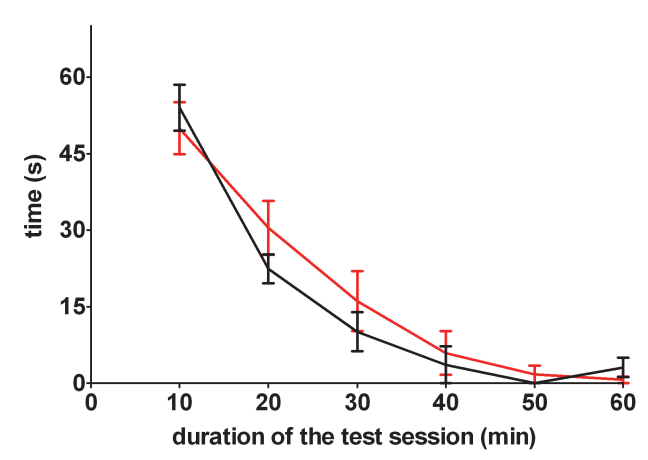

Distance

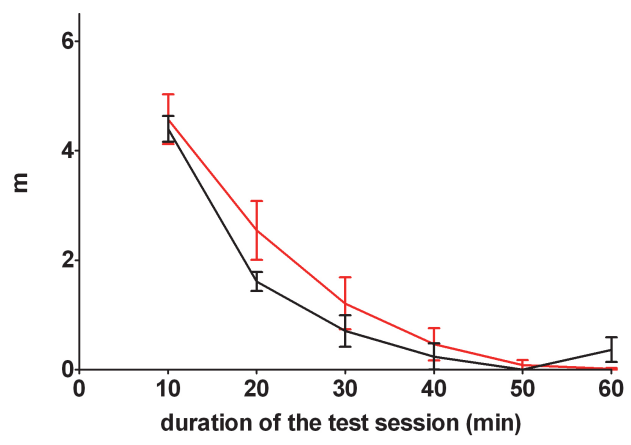

Rearing

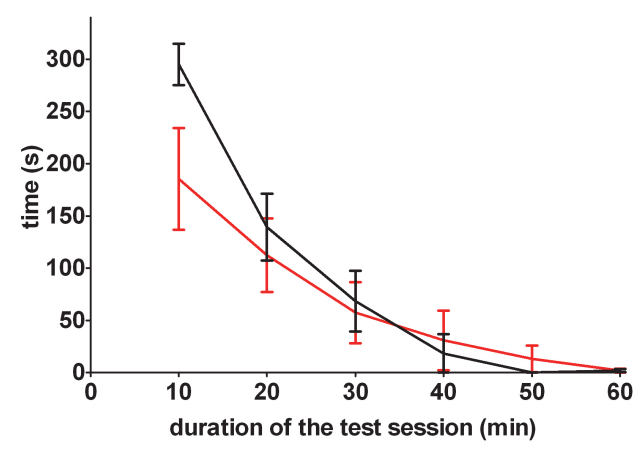

Grooming

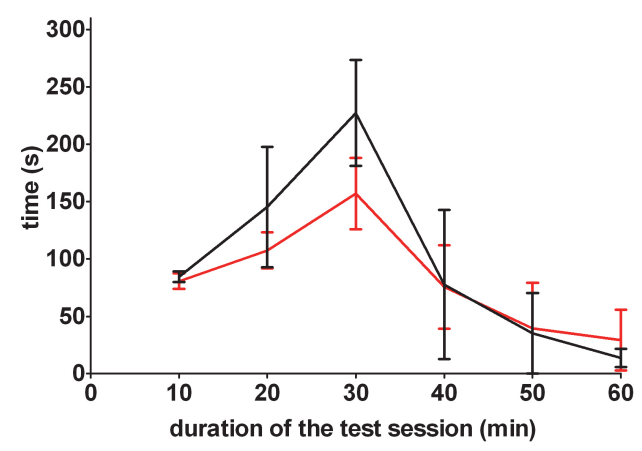

Average speed
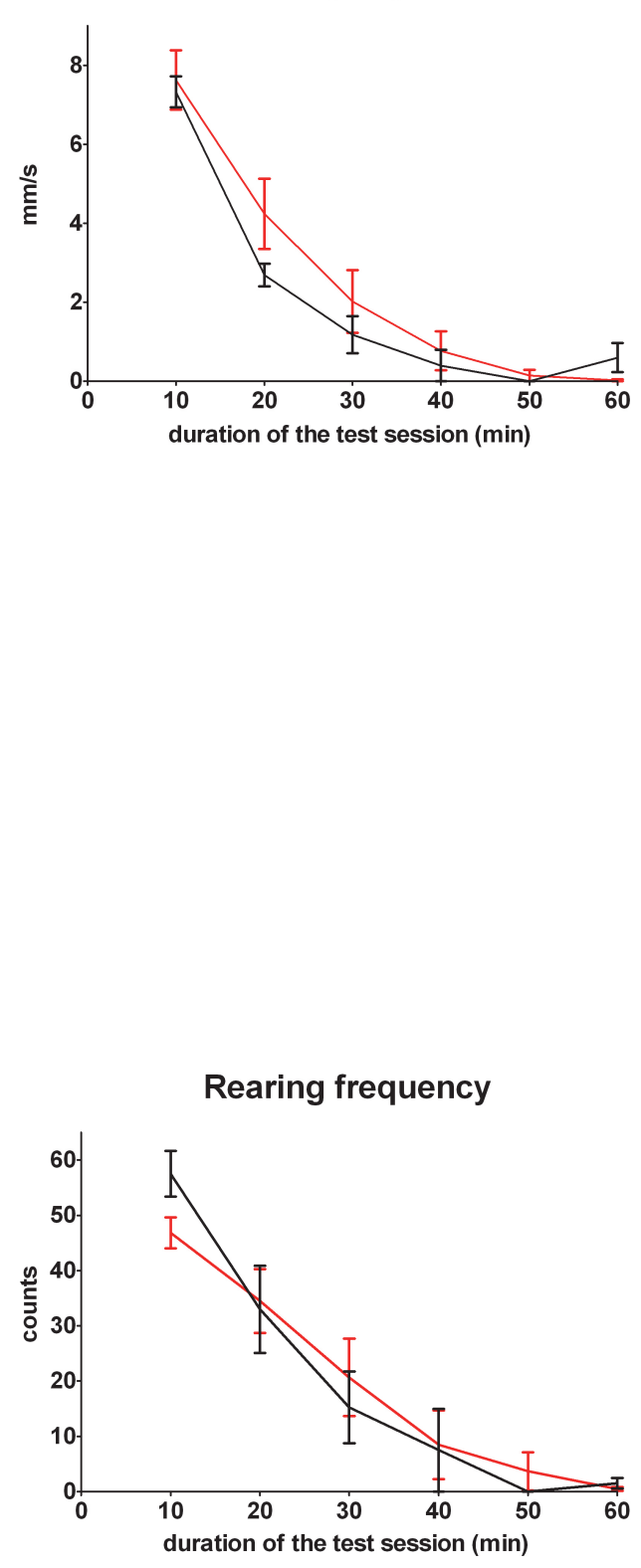

Grooming frequency

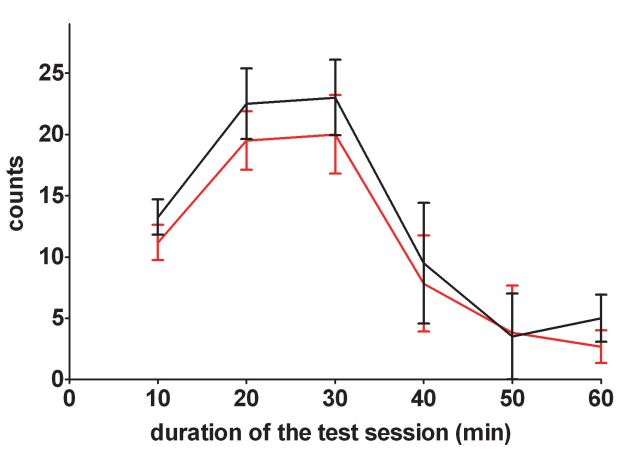

Fig. 2. Test day 2 - PND 42: Effects of single DA injection over PND 10-14 on vertical and horizontal activity and comfort behavior. The one hour session was divided into six 10-min intervals. Red lines represent DA treated rats, black lines saline treated rats. Error bars were calculated as \pm SEM. 


\section{test day 3 - PND 112}

Locomotion

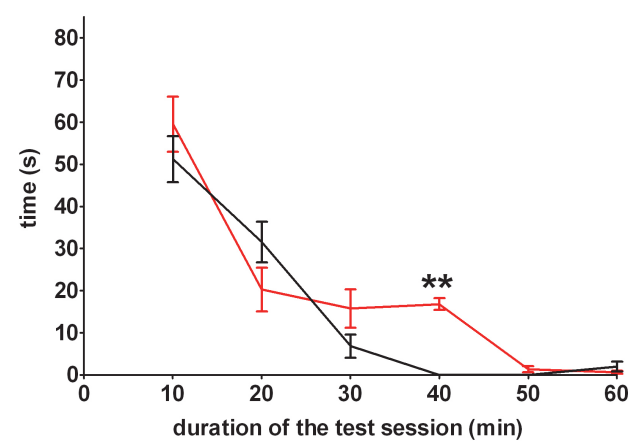

Distance

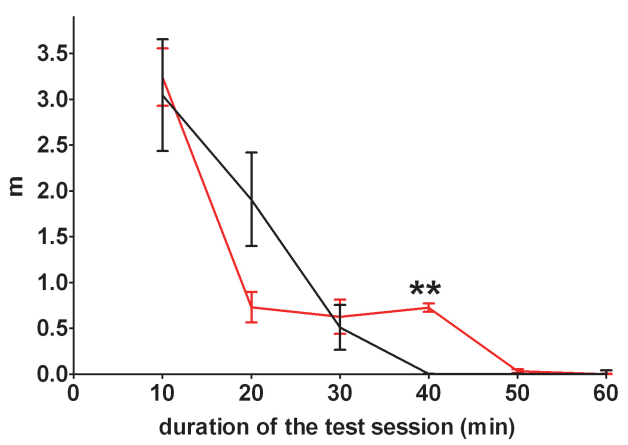

Rearing

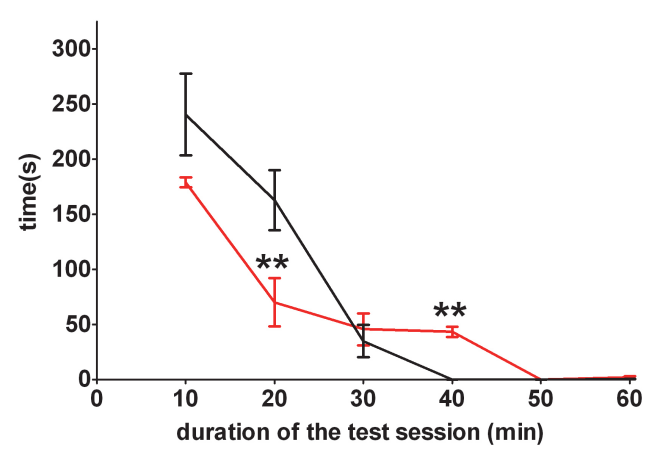

Grooming

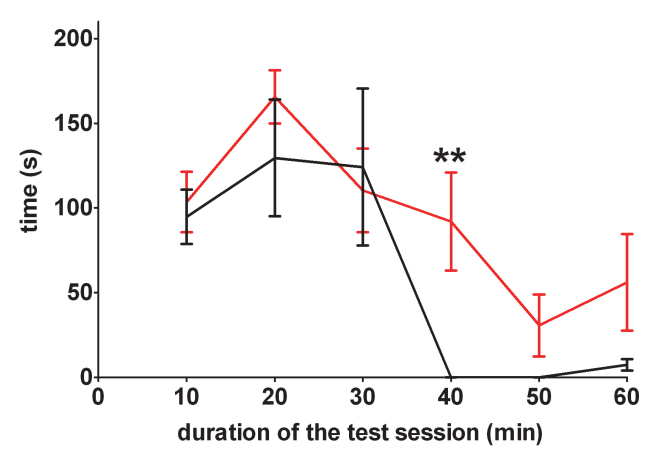

Average speed

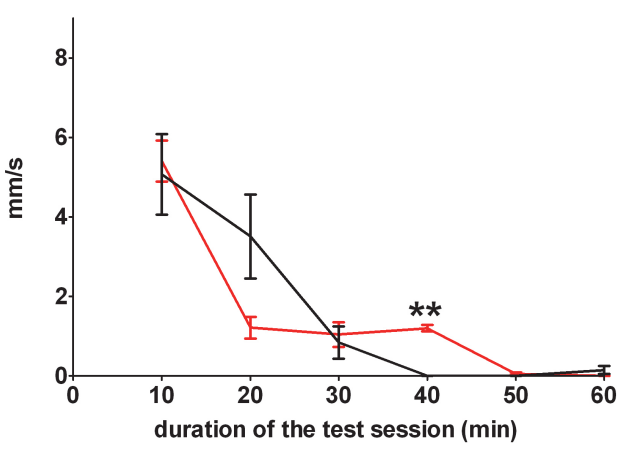

Rearing frequency

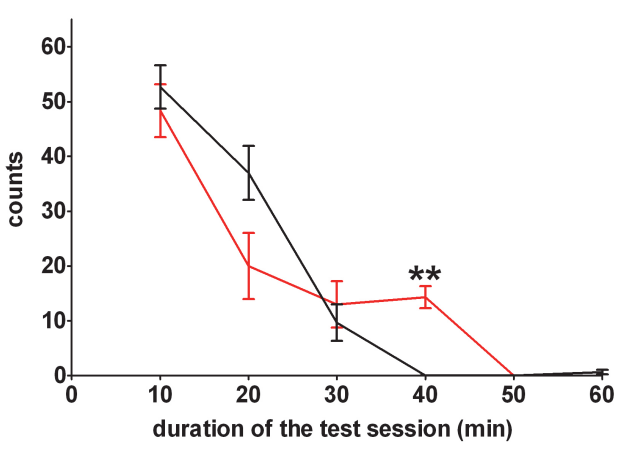

Grooming frequency

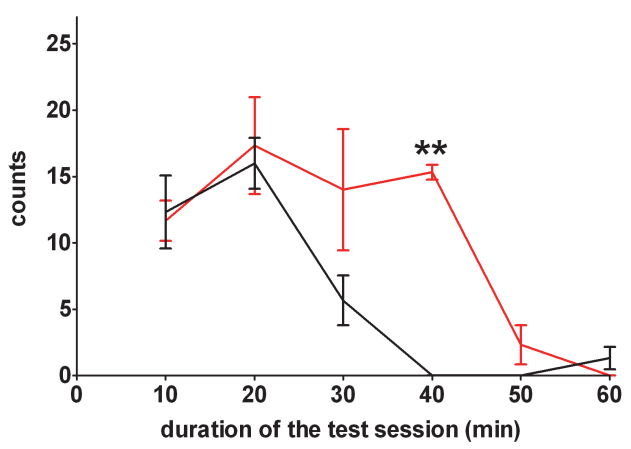

Fig. 3. Test day 3 - PND 112: Effects of single DA injection over PND 10-14 on vertical and horizontal activity and comfort behavior. The one hour session was divided into six 10-min intervals. Red lines represent DA treated rats, black lines saline treated rats. * Differences significant at $\mathrm{p}<0.05, * *$ differences significant at $\mathrm{p}<0.01$. Error bars were calculated as \pm SEM. 
increased locomotor activity of adult female rats at PND 150 exposed to low doses of DA between PND 8-14. Many studies have confirmed the changes in motor activity and cognitive function after administration of DA, these changes are accompanied by neurological symptoms and neurodegeneration in specific brain regions and the toxicity associated with DA is thought to be attributed to an interaction with kainate receptors (Tryphonas et al. 1990, Sobotka et al. 1996, Appel et al. 1997, Pulido 2008, Schwarz et al. 2014).

Results of our study confirmed that very low doses of DA administered during critical developmental periods have no direct toxic effect (weight gain of the DA animals was not affected), but cause a change in behavioral pattern and these changes depend on the age of animals with the manifestation in the adulthood. The exact explanation for this phenomenon is not simple. On one side in the first weeks of postnatal life excitatory processes predominate and glutamate plays a key role in neurotrophic differentiation, synaptogenesis and manages the development of neuronal cytoarchitecture (McDonald and Johnston 1990). Presence of kainate receptors therefore plays an important role in the normal and abnormal functioning of the CNS (Bahn et al. 1994), and a mild activation of KA receptors in the perinatal period can, together with the absence of inhibitory mechanisms (Leinekugel et al. 1999) significantly interfere with the process of neuroplasticity. On the other hand, it should be noted that NMDA and non-NMDA receptors may cause release of the neurotransmitter dopamine in the mesocorticolimbic pathway, which, according to some authors, is the pathway responsible for the behavior in the open field arena (Crowder and Weiner 2002, Breese et al. 2005). Change in the functional integrity of the dopamine system in the midbrain only, can cause changes in the locomotor activity and habituation that were described in our results.

We conclude that moderate activation of KA receptors by DA during critical developmental period induces behavioral changes that persist into adulthood.

\section{Conflict of Interest}

There is no conflict of interest.

\section{Acknowledgements}

This study was supported by grant PRVOUK-P34/LF1/7.

\section{References}

ADAMS AL, DOUCETTE TA, RYAN CL: Altered pre-pulse inhibition in adult rats treated neonatally with domoic acid. Amino Acids 35: 157-160, 2008.

ADAMS AL, DOUCETTE TA, JAMES R, RYAN CL: Persistent changes in learning and memory in rats following neonatal treatment with domoic acid. Physiol Behav 96: 505-512, 2009.

APPEL NM, RAPOPORT SI, O'CALLAGHAN JP: Sequelae of parenteral domoic acid administration in rats: comparison of effects on different anatomical markers in brain. Synapse 25: 350-358, 1997.

BAHN S, VOLK B, WISDEN W: Kainate receptor gene expression in the developing rat brain. J Neurosci 14: 5525 5547, 1994.

BERMAN FW, MURRAY TF: Domoic acid neurotoxicity in cultured cerebellar granule neurons is mediated predominantly by NMDA receptors that are activated as a consequence of excitatory amino acid release. J Neurochem 69: 693-703, 1997.

BERNARD PB, MACDONALD DS, GILL DA, RYAN CL, TASKER RA: Hippocampal mossy fiber sprouting and elevated trkB receptor expression following systemic administration of low dose domoic acid during neonatal development. Hippocampus 17: 1121-1133, 2007.

BREESE GR, KNAPP DJ, CRISWELL HE, MOY SS, PAPADEAS ST, BLAKE BL: The neonate-6hydroxydopamine-lesioned rat: a model for clinical neuroscience and neurobiological principles. Brain Res Brain Res Rev 48: 57-73, 2005.

BURT MA, RYAN CL, DOUCETTE TA: Altered responses to novelty and drug reinforcement in adult rats treated neonatally with domoic acid. Physiol Behav 93: 327-336, 2008.

CHANDRASEKARAN A, PONNAMBALAM G, KAUR C: Domoic acid-induced neurotoxicity in the hippocampus of adult rats. Neurotox Res 6: 105-117, 2004.

COSTA LG, GIORDANO G, FAUSTMAN EM: Domoic acid as a developmental neurotoxin. Neurotoxicology 31: 409-423, 2010.

CROWDER TL, WEINER JL: Functional characterization of kainate receptors in the rat nucleus accumbens core region. J Neurophysiol 88: 41-48, 2002. 
DOBBING J, SANDS J: Comparative aspects of the brain growth spurt. Early Hum Dev 3: 79-83, 1979.

DOUCETTE TA, BERNARD PB, YUILL PC, TASKER RA, RYAN CL: Low doses of non-NMDA glutamate receptor agonists alter neurobehavioural development in the rat. Neurotoxicol Teratol 25: 473-479, 2003.

DOUCETTE TA, BERNARD PB, HUSUM H, PERRY MA, RYAN CL, TASKER RA: Low doses of domoic acid during postnatal development produce permanent changes in rat behaviour and hippocampal morphology. Neurotox Res 6: 555-563, 2004.

GIORDANO G, WHITE CC, MCCONNACHIE LA, FERNANDEZ C, KAVANAGH TJ, COSTA LG: Neurotoxicity of domoic Acid in cerebellar granule neurons in a genetic model of glutathione deficiency. Mol Pharmacol 70: 2116-2126, 2006.

GIORDANO G, WHITE CC, MOHAR I, KAVANAGH TJ, COSTA LG: Glutathione levels modulate domoic acid induced apoptosis in mouse cerebellar granule cells. Toxicol Sci 100: 433-444, 2007.

GIORDANO G, LI L, WHITE CC, FARIN FM, WILKERSON HW, KAVANAGH TJ, COSTA LG: Muscarinic receptors prevent oxidative stress-mediated apoptosis induced by domoic acid in mouse cerebellar granule cells. J Neurochem 109: 525-538, 2009.

GRANT KS, BURBACHER TM, FAUSTMAN EM, GRATTTAN L: Domoic acid: neurobehavioral consequences of exposure to a prevalent marine biotoxin. Neurotoxicol Teratol 32: 132-141, 2010.

IVERSON F, TRUELOVE J, NERA E, TRYPHONAS L, CAMPBELL J, LOK E: Domoic acid poisoning and musselassociated intoxication: preliminary investigations into the response of mice and rats to toxic mussel extract. Food Chem Toxicol 27: 377-384, 1989.

LEINEKUGEL X, KHALILOV I, MCLEAN H, CAILLARD O, GAIARSA JL, BEN-ARI Y, KHAZIPOV R: GABA is the principal fast-acting excitatory transmitter in the neonatal brain. Adv Neurol 79: 189-201, 1999.

LEVIN ED, PIZZARO K, PANG WG, HARRISON J, RAMSDELL JS: Persisting behavioral consequences of prenatal domoic acid exposure in rats. Neurotoxicol Teratol 27: 719-725, 2005.

MARRIOTT AL, RYAN CL, DOUCETTE TA: Neonatal domoic acid treatment produces alterations to prepulse inhibition and latent inhibition in adult rats. Pharmacol Biochem Behav 103: 338-344, 2012.

MCDONALD JW, JOHNSTON MV: Physiological and pathophysiological roles of excitatory amino acids during central nervous system development. Brain Res Brain Res Rev 15: 41-70, 1990.

PENG YG, RAMSDELL JS: Brain Fos induction is a sensitive biomarker for the lowest observed neuroexcitatory effects of domoic acid. Fundam Appl Toxicol 31: 162-168, 1996.

PERL TM., BEDARD L, KOSATSKY T, HOCKIN JC, TODD EC, REMIS RS: An outbreak of toxic encephalopathy caused by eating mussels contaminated with domoic acid. New Engl J Med 322: 1775-1780, 1990.

PERRY MA, RYAN CL, TASKER RA: Effects of low dose neonatal domoic acid administration on behavioural and physiological response to mild stress in adult rats. Physiol Behav 98: 53-59, 2009.

PULIDO O: Domoic acid toxicologic pathology: a review. Marine Drugs 6: 180-219, 2008.

SCALLET AC, BINIENDA Z, CAPUTO FA, HALL S, PAULE MG, ROUNTREE RL, SCHMUED L, SOBOTKA T, SLIKKER W Jr: Domoic acid-treated cynomolgus monkeys (M. fascicularis): effects of dose on hippocampal neuronal and terminal degeneration. Brain Res 627: 307-313, 1993.

SCHWARZ M, JANDOVÁ K, STRUK I, MAREŠOVÁ D, POKORNÝ J, RILJAK V: Low dose domoic acid influences spontaneous behavior in adult rats. Physiol Res 63: 369-376, 2014.

SOBOTKA TJ, BROWN R, QUANDER DY, JACKSON R, SMITH M, LONG SA, BARTON CN, ROUNTREE RL, HALL S, EILERS P, JOHANNESSEN JN, SCALLET AC: Domoic acid: neurobehavioral and neurohistological effects of low-dose exposure in adult rats. Neurotoxicol Teratol 18: 659-670, 1996.

STEWART GR, ZORUMSKI CF, PRICE MT, OLNEY JW: Domoic acid: a dementia-inducing excitotoxic food poison with kainic acid receptor specifity. Exp Neurol 110: 127-138, 1990.

TODD ECD: Domoic acid and amnesic shellfish poisoning - a review. Food Prot 56: 69-83, 1993.

TRYPHONAS L, TRUELOVE J, IVERSON F, TODD EC, NERA EA: Neuropathology of experimental domoic acid poisoning in non-human primates and rats. Can Dis Wkly Rep 16: 75-81, 1990.

WRIGHT JLC, BOYD RK, DE FREITAS ASW, FALK M, FOXALL RA, JAMIESON WD: Identification of domoic acid, a neuroexcitatory amino acid, in toxic mussels from eastern Prince Edward Island. Can J Chem 68: 481490, 1989. 